\title{
Defensive medicine starts at the top in United States
}

Published at www.cmaj.ca on Apr. 15

$\mathrm{T}$ he 48-year-old man who came in for his routine check-up seemed the picture of health: fit guy, loves basketball, no sickly past. Yet his doctors performed a battery of tests that raised eyebrows in United States medical circles.

The patient had a colonoscopy normally done for older men, a calciumdeposit heart scan usually reserved for higher-risk patients and a prostate cancer screening test no longer routinely recommended, as well as all the everyday tests that are part of normal medical examinations.

Call it defensive medicine from the top down. The patient was President Barack Obama, who recently overhauled the American health care system but left one problem area untouched: the impulse to go overboard with expensive and invasive procedures of questionable benefit.

American presidents, of course, get the ultimate in care. But in a country that wastes billions on unnecessary tests, Obama's doctors set an unexpectedly controversial example in his physical and, in some minds, conceivably imperiled his future health with excess radiation.

In such a litigious society, physicians are drawn to a cover-all-the-bases ethic in the examining room. The fear of malpractice lawsuits and huge jury awards for errant diagnoses are driving up costs for health insurance, malpractice insurance and the taxpayer. That can wear doctor-patient trust thin.

"It's like an acid that's been poured over the culture of health care delivery in America," said Philip K. Howard, chairman of Common Good, a nonprofit legal reform coalition, and author of Living Without Lawyers.

"Medical litigation is a polarizing process," he adds, and one that "terrifies doctors to such an extent that when they see a patient, they think of that patient as a potential plaintiff." His organiza-

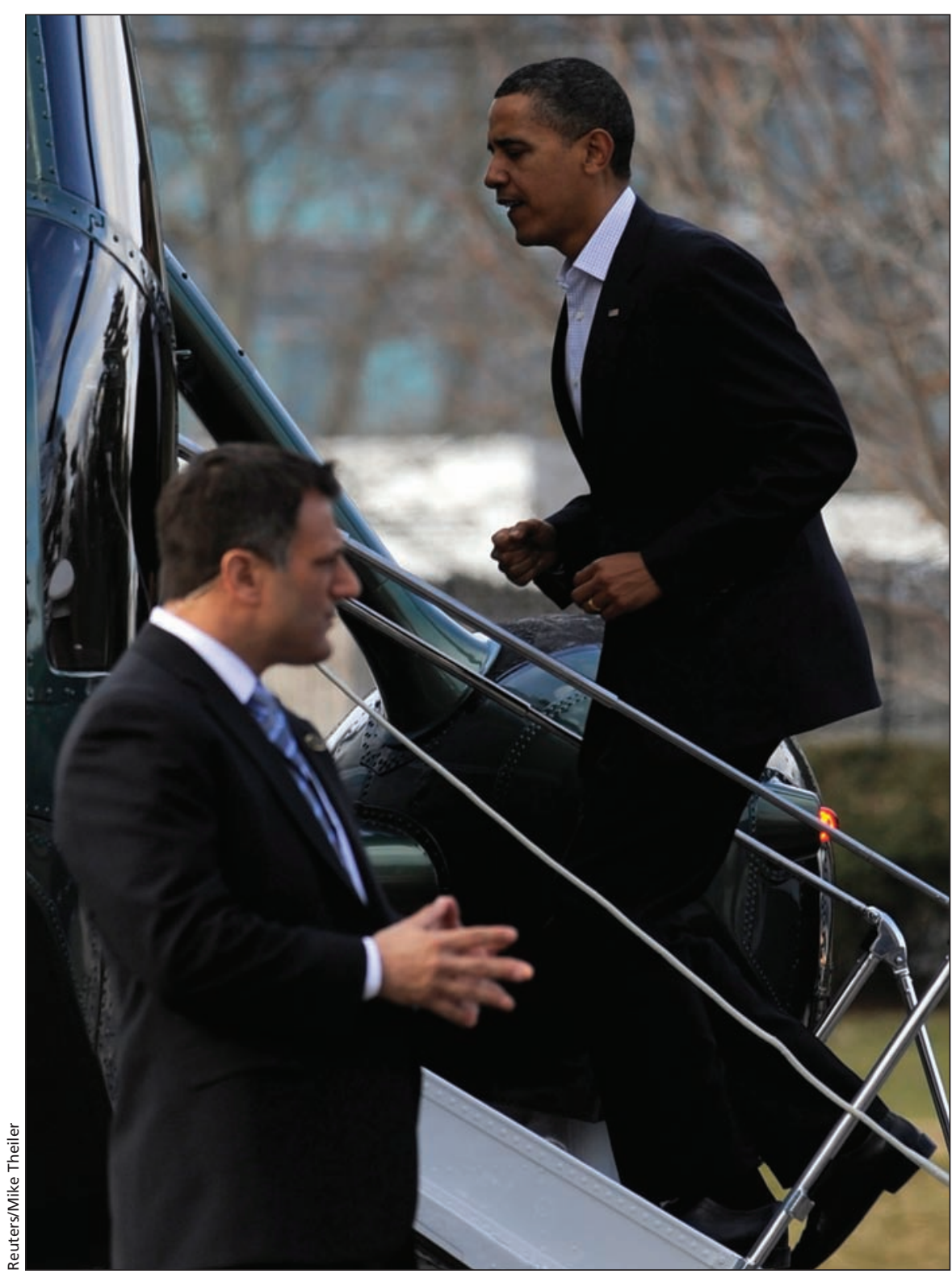

United States President Barack Obama boards Marine One as he departs the National Naval Medical Center in Bethesda, Maryland, where he underwent a routine physicial examination on Feb. 2.

tion supports establishing special health courts to adjudicate malpractice suits in place of judges and juries.

Congressional budget analysts calculate that limits on jury awards would save the Washington US\$5.4 billion annually because doctors serving the elderly and poor under government insurance would order fewer unnecessary tests to protect themselves from litigation. The American Medical Association (AMA) estimates defensive medicine raises health care costs at least US\$84 billion a year.

But tort reform, as it's called, clashes with the interests of trial lawyers, who are 
heavy donors to Obama's Democratic Party and oppose curbs on legal remedies for victims of medical mistakes (CMAJ 2009. DOI:10.1503/cmaj.090129).

Their central point: At least 44000 Americans die in the hospital each year from botched procedures or diagnoses. With pressure intensifying to save money everywhere in health care, they argue, the unfettered ability to sue and win big is a vital counterweight to the rationing of services as well as to outright physician incompetence.

There's little question US doctors have to look over their shoulder.

A 2006 survey found that American physicians were much more likely to be sued than their Canadian counterparts (Arch Intern Med. 2006;166:2605-11) As well, US doctors are more likely to face crushing penalties if successfully sued, and they pay higher premiums for legal protection.

Obama is fresh off a landmark achievement in health care (CMAJ 2010. DOI:10.1503/cmaj.109-3222). His reforms establish a right to health insurance for every American, an obligation for most to carry it, new ways for people to buy coverage and measures to root out waste.

Tort reform, pushed for years by Republicans, came to little during the recent health care brouhaha.

At the 11th hour, Obama backed a
Republican-inspired proposal for experimental health courts. Earlier, he'd won US\$25 million in seed money for states to try alternatives to mainstream litigation. But the final health care reform bill dropped the notion of experimental health courts and left litigation reform for another day.

It remains a prime goal of the medical profession. The AMA, which wants a US\$250 000 cap on noneconomic damages, says it costs more than US\$110 000 to fight an average case that goes through trial. More than $90 \%$ of such cases find no physician negligence, the AMA says.

In Obama's instance, his doctors at Bethesda Naval Hospital were surely less worried about being sued by a fussy patient than about leaving anything to chance with their commanderin-chief.

But Dr. Rita F. Redberg, editor of the Archives of Internal Medicine, asserted that for the president and everyone else, "more care is not necessarily better care." She questioned Obama's electron beam computed tomographic scan for coronary calcium, which the US Preventive Services Task Force recommends against for low-risk men because of uncertain benefit and the radiation risk. Obama also received a virtual colonoscopy, a procedure not yet universally endorsed. And it was done two years before the recommended age for a routine colonoscopy or fecal blood test. In addition, his PSA test for prostate cancer is no longer recommended as a matter of course for any age. "Mr. Obama's case is multiplied many times over at extraordinary cumulative cost to society and personal cost to the individuals who receive tests with known adverse effects and potential harms but without benefits," Redberg wrote in an editorial. (Arch Intern Med 2010;170[7]:583).

The White House noted that a colonoscopy is sometimes indicated for younger African-Americans. As well, the virtual colonoscopy required no sedation, avoiding a situation in which the president might have had to transfer power temporarily.

Obama was declared in "excellent" health by doctors, who noted borderline high total cholesterol (238), a healthy resting and seated blood pressure of $105 / 62$, a good body mass index of 23.7 and tendonitis in his left leg.

The president takes nicotine replacement, though, and acknowledges sneaking the occasional cigarette. Doctors advised him to exercise his own defensive medicine here: Quit smoking. - Cal Woodward, Washington DC

DOI:10.1503/cmaj.109-3236 